\title{
Expression of ECM proteins fibulin-1 and -2 in acute and chronic liver disease and in cultured rat liver cells
}

\author{
Fabio Piscaglia • József Dudás • Thomas Knittel • Paola Di Rocco • Dominik Kobold • \\ Bernhard Saile • Maria Assunta Zocco • Rupert Timpl • Giuliano Ramadori
}

Received: 23 January 2009 / Accepted: 25 May 2009 /Published online: 17 July 2009

(C) The Author(s) 2009. This article is published with open access at Springerlink.com

\begin{abstract}
Fibulin-2 has previously been considered as a marker to distinguish rat liver myofibroblasts from hepatic stellate cells. The function of other fibulins in acute or chronic liver damage has not yet been investigated. The
\end{abstract}

The work was supported by SFB 402 funding.

Fabio Piscaglia and József Dudás contributed equally to this work.

Rupert Timpl died in 2003.

This article is dedicated to Professor Karl-Hermann Meyer zu

Büschenfelde on the occasion of his 80th birthday.

F. Piscaglia · J. Dudás · T. Knittel • P. Di Rocco $\cdot$ D. Kobold $\cdot$

B. Saile $\cdot$ M. A. Zocco $\cdot$ G. Ramadori

Department of Internal Medicine and Gastroenterology,

University of Göttingen,

Robert-Koch-Strasse 40,

37075 Göttingen, Germany

R. Timpl

Max-Planck-Institut für Biochemie,

82152 Martinsried, Germany

G. Ramadori $(\bowtie)$

Department of Gastroenterology and Endocrinology,

Robert-Koch-Strasse 40,

37075 Göttingen, Germany

e-mail: gramado@med.uni-goettingen.de

Present Address:

F. Piscaglia

Divisione di Medicina Interna - Bolondi, University of Bologna,

Via Albertoni 15,

40138 Bologna, Italy

Present Address:

J. Dudás

Department of Otorhinolaryngology,

Medical University of Innsbruck,

Anichstrasse 35,

6020 Innsbruck, Austria aim of this study has been to evaluate the expression of fibulin- 1 and -2 in models of rat liver injury and in human liver cirrhosis. Their cellular sources have also been investigated. In normal rat liver, fibulin-1 and -2 were both mainly present in the portal field. Fibulin-1-coding transcripts were detected in total RNA of normal rat liver, whereas fibulin-2 mRNA was only detected by sensitive, real-time quantitative polymerase chain reaction. In acute liver injury, the expression of fibulin-1 was significantly increased (17.23-fold after $48 \mathrm{~h}$ ), whereas that of fibulin-2 was not modified. The expression of both fibulin-1 and -2 was increased in experimental rat liver cirrhosis (19.16- and 26.47-fold, respectively). At the cellular level, fibulin-1 was detectable in hepatocytes, "activated" hepatic stellate cells, and liver myofibroblasts (2.71-, 122.65-, and 469.48fold over the expression in normal rat liver), whereas fibulin-2 was restricted to liver myofibroblasts and was regulated by transforming growth factor beta-1 (TGF$\beta 1)$ in 2-day-old hepatocyte cultures and in liver myofibroblasts. Thus, fibulin-1 and -2 respond differentially to single and repeated damaging noxae, and their expression is differently present in liver cells. Expression of the fibulin- 2 gene is regulated by TGF- $\beta 1$ in liver myofibroblasts.

Keywords Carbon tetrachloride - Extracellular matrix . Hepatic stellate cells · Liver cirrhosis · Liver myofibroblasts . Rat (Wistar) · Human

\section{Introduction}

Liver fibrogenesis represents the uniform response of the liver to toxic, infectious, or metabolic agents and is characterized by an increased synthesis and altered depo- 
sition of newly formed extracellular matrix (ECM) components (Ramadori et al. 1998). In liver fibrosis, the composition in expanded portal areas, septa, and cirrhotic nodules is similar to that of the normal portal tracts and consists of collagens, various members of the structural glycoprotein family, the major subclasses of glycosaminoglycans, and elastin. In addition to these classical matrix components, members of the coagulation system, such as fibrinogen/fibrin, plasmin, and von Willebrand factor (vWF; Knittel et al. 1995; Neubauer et al. 1995), participate in hepatic tissue repair. The deposition of fibrin/fibronectin seems to be an early event in hepatic injury (Neubauer et al. 1995) and might provide a pacemaker function during liver fibrogenesis (Martinez-Hernandez 1985). However, the exact temporal sequence of ECM protein deposition still needs to be clarified, and possibly even the list of the main ECM proteins involved in the repair processes is still incomplete.

The fibulins are an emerging family of ECM proteins characterized by tandem arrays of calcium-binding epidermal growth factor (EGF)-like domains and a unique C-terminal structure (Timpl et al. 2003) and are a broadly conserved component of the ECM (Hesselson and Kimble 2006). They were first discovered in 1989 (see Argraves et al. 2003). To date, fibulin-1 and -2 represent those characterized in more detail (Timpl et al. 2003) and have been shown to display distinct, yet overlapping, molecular interactions and expression patterns, whereas fibulins 3-6 are less-well defined (Argraves et al. 2003). Both fibulin-1 and -2 are localized in basement membranes, elastic fibers, and other connective tissue structures. Fibulin-1 is also a plasma protein, and its gene-expression can be detected early during embryonic development in most basement membranes. Expression of the fibulin-2 gene is initiated later during embryonic development and is distributed in a more restricted manner than that of fibulin-1 (Zhang et al. 1996).

Considerable evidence is available supporting a role for fibulins within the ECM; indeed, they have been found in various tissues in association with elastic fibers, basement membrane networks, fibronectin microfibrils, and proteoglycan aggregates (Roark et al. 1995; Sasaki et al. 1995a, b; Reinhardt et al. 1996; Timpl et al. 2003; Argraves et al. 2003).

Mammalian fibulin-1 has been shown to be an important component of blood vessel walls and to be a ligand for a diverse group of extracellular proteins (Argraves et al. 2003). Fibulin-2 is present in the basement membrane and stroma of many tissues, and its expression pattern suggests an essential role in organogenesis, particularly in embryonic heart development (Tsuda et al. 2001). Recently, fibulin-2 has been shown to be produced by smooth muscle cells, as a response to injury, and may participate in the ECM organization that regulates the migration of smooth muscle cells during the repair of vessel walls (Strom et al. 2006).
We have previously reported the identification and cellular expression of fibulin-2, as a marker of alpha-smooth muscle$\operatorname{actin}^{+}\left(\mathrm{SMA}^{+}\right)$myofibroblasts (MFs) in rat liver (Knittel et al. 1999a). Fibulin-2-positive MFs have been detected in the portal field, vessel walls, and hepatic parenchyma of the normal liver, and their number is increased in the septal regions during liver fibrogenesis (Knittel et al. 1999b).

Little is known about the hepatic localization and expression of fibulin-1 in normal adult liver (Zhang et al. 1996), and no data are available concerning fibulin-1 and -2 in human liver diseases. The inflammatory response to liver damage involves an important participation of the ECM (Ramadori 1991; Knittel and Ramadori 1994; Baumann and Gauldie 1994; Desmouliere and Gabbiani 1994; Gressner and Bachem 1995; Pinzani 1995) and fibrogenetic processes. Furthermore, the hepatic cellular sources of fibulin-1 based on the study of liver cell cultures have not been described as yet. In particular, whether fibulin-1 shares with fibulin-2 a specificity for $\mathrm{SMA}^{+} \mathrm{MFs}$ remains to be investigated. Hence, we have carried out a comparative investigation of the gene expression and localization of fibulin-1 and -2 in normal liver, during short term liver injury, in cirrhotic livers, and in various types of liver cell culture.

\section{Materials and methods}

Animals

Liver cells were isolated from female Wistar rats (Charles River, Sulzfeld, Germany) maintained under 12-h light/ dark cycles, with food and water being provided ad libitum. In carrying out the in vivo experiments described in this report, all animals received humane care in compliance with the institutions' guidelines and those of the National Institutes of Health.

\section{Reagents}

Chemicals were obtained from the following sources: Dulbecco's modification of Eagle's medium (DMEM), M199 medium, and fetal calf serum (FCS) from Flow Laboratories (Bonn, Germany); endothelial cell basal medium (ECBM), human basic fibroblast growth factor (hbFGF), and human EFG from PromoCell (Heidelberg, Germany); pronase E from Merck (Darmstadt, Germany); collagenase from Clostridium histolyticum (used for hepatocyte isolations), random prime labeling kit, and dNTPs from Boehringer (Mannheim, Germany); insulin S from Hoechst (Frankfurt, Germany). Nycodenz was from Nyegaard (Oslo, Norway). Collagenase type I, collagen type I (from rat tail), transforming growth factor beta-1 (TGF- $\beta 1$ ) repared from human platelets, and dexamethasone were 
from Sigma (Munich, Germany). ${ }^{35} \mathrm{~S}$-labeled dATP, ${ }^{32} \mathrm{P}$ dCTP, nick translation kit, and Hybond $\mathrm{N}$ membranes were obtained from Amersham Buchler (Braunschweig, Germany). Reagents for the random arbitrarily primed (RAP) polymerase chain reaction (PCR) were from Stratagene (Heidelberg, Germany), Moloney murine leukaemia virus reverse transcriptase and first-strand synthesis buffer were purchased from Gibco BRL (Karlsruhe, Germany). The TA cloning kit, MMLV reverse transcriptase, and Sybr Green reaction master mix were purchased from Invitrogen (San Diego, Calif., USA). The DNA sequencing kit was from Perkin Elmer (Foster City, Calif., USA).

\section{Antibodies}

The mouse antibodies $(\mathrm{mAb})$ against alpha smooth muscle actin (SMA) and the tetramethylrhodamine isothiocyanate (TRITC)- or fluorescein isothiocynate (FITC)-conjugated anti-mouse and anti-rabbit IgGs were from Sigma (Munich, Germany). The Alexa (488 and 555)-conjugated anti-mouse and anti-rabbit IgGs were from Invitrogen. The rabbit Ig to human vWF (factor VIII) was from Dako (Copenhagen, Denmark). Rabbit Ig directed against human fibronectin were purchased from Boehringer Mannheim (Mannheim, Germany). The rabbit IgG directed against mouse fibulin1C (Sasaki et al. 1995a), against mouse fibulin-2 (Pan et al. 1993a, b) and human fibulin-2 (Sasaki et al. 1995b) were as previously described. Double-staining was performed for fibulin-1/-2 and vWF by indirect immunofluorescence.

Induction of acute and chronic liver damage

Rats were given carbon tetrachloride $\left(\mathrm{CCl}_{4}\right)$ /maize oil solution $(50 \% \mathrm{vol} / \mathrm{vol})$ by oral administration as previously described (Knittel et al. 1992a; Neubauer et al. 1995, 1996). the $\mathrm{CCl}_{4}$ dosage was $75 \mu \mathrm{l} / 100 \mathrm{~g}$ body weight. Control animals were treated with maize oil only. In each group, animals were killed at 3, 6, 9, 12, 24, 48, 72, and $96 \mathrm{~h}$ after a single high-dose of $\mathrm{CCl}_{4}$. The liver was perfused with saline solution $(0.9 \% \mathrm{NaCl})$ and snap-frozen in liquid nitrogen. Massive liver necrosis was observed $24-48 \mathrm{~h}$ after a single dose of $\mathrm{CCl}_{4}$. The necrotic areas were more conspicuous in zone 3 Rappaport.

For the induction of liver fibrosis, chronic damage, and regeneration, animals (male and female Wistar rats weighing approximately $200 \mathrm{~g}$ ) were exposed to an oral application of $\mathrm{CCl}_{4}$ once a week for a period of 12 to 17 weeks. At the end of the treatment, the liver was removed and snap-frozen in liquid nitrogen. The frozen specimens were used for RNA isolation and immunohistochemical studies (Dudas et al. 2009). For acute liver injury, three series were analyzed, whereas for chronic liver injury, five series were investigated.
Human liver tissue

Three specimens of normal human livers were obtained from non-cancerous tissue, surrounding surgically resected liver metastases. Three specimens of cirrhotic human livers were obtained from patients undergoing transplantation for advanced viral cirrhosis. Specimens were frozen in liquid nitrogen immediately after surgical removal. The study protocol was in accordance with the Declaration of Helsinki and approved by the local ethical committee.

\section{Immunochemistry and cytochemistry}

Frozen tissue sections $(7 \mu \mathrm{m})$ of normal or acutely or chronically damaged rat liver specimens and of normal and cirrhotic human livers were fixed in methanol/acetone $(5 \mathrm{~min} /$ $10 \mathrm{~s}$ at $-20^{\circ} \mathrm{C}$ ), air-dried for $45 \mathrm{~min}$, and stored at $-20^{\circ} \mathrm{C}$, as described elsewhere (Knittel et al. 1992a, b, 1996a, b; Ramadori et al. 1990, 1991). Cells cultured in LAB-TEK slide chambers were fixed by the same procedure. Cells or tissue sections were examined by indirect immunochemistry. Slides were preincubated with goat serum for $45 \mathrm{~min}$ at $37^{\circ} \mathrm{C}$ to reduce unspecific staining. After extensive washes in phosphate-buffered saline (PBS), cells or tissue sections were incubated with specific primary antibodies for $1 \mathrm{~h}$ at $37^{\circ} \mathrm{C}$ in a humidified atmosphere and washed three times with PBS. Samples were covered with peroxidase- or fluorescent-compound-conjugated secondary antibodies for $1 \mathrm{~h}$ at $37^{\circ} \mathrm{C}$ followed by extensive washes in PBS. The secondary antibodies used were: anti-rabbit Alexa-555 (Molecular Probes, Karlsruhe, Germany; excitation $555 \mathrm{~nm}$, emission $565 \mathrm{~nm}$ ), anti-rabbit-FITC (Sigma, Steinheim Germany; excitation $494 \mathrm{~nm}$, emission $518 \mathrm{~nm}$ ), and anti-rabbit-TRITC (Sigma; excitation $557 \mathrm{~nm}$, emission $576 \mathrm{~nm}$ ). For indirect immunofluorescence, samples were mounted with Fluoromount (Southern Biotechnology, Birmingham, Ala., USA). When peroxidase-labeled secondary antibodies were used, tissue sections were incubated with PBS containing diaminobenzidine $(0.5 \mathrm{mg} / \mathrm{ml})$ and $\mathrm{H}_{2} \mathrm{O}_{2}$ $(0.01 \%)$ solution, counterstained in Meyer's hemalum, and washed again before being covered with a coverslip. Antibodies were diluted in PBS containing $0.1 \%$ bovine serum albumin. Non-specific staining was controlled by incubation with isotype-specific control rabbit or mouse IgGs instead of the specific primary antibodies.

\section{cDNA probes}

Fibulin-1 A 274-bp-long cDNA generated by reverse transcription with the PCR (RT-PCR) in rat liver MFderived samples was employed for Northern blot analysis. Primers for the RT-PCR were designed by using the program "prime" of the Wisconsin package of the genetics 
computer group (Devereux et al. 1984) as follows: forward primer, 5'-GTA TTC ATA ACT GCC CCC-3'; reverse primer, 5'-CAC TCA TCC ACA TCA ACA C-3', corresponding to the published nucleotide sequence of the mouse mRNA for fibulin-1, positions 935 and 1208 (AC X70854; Pan et al. 1993a). This tract is situated in the EGFlike repeats region, which is highly preserved in various mammals, such as humans and mice (Pan et al. 1993a, b) and is common to all the variants of fibulin-1 (Pan et al. 1993a; Tran et al. 1997b). The PCR product, expected to encode the corresponding EGF-like repeats tract of the rat sequence for fibulin-1, was cloned into pCR2.1 cloning vector by using the TA cloning kit and sequenced. The obtained sequence showed a 97.4\% homology with the mouse fibulin-1 sequence.

Fibulin-2 The 504-bp-long cDNA fragment generated by the differential display method in rat MF (Knittel et al. 1999a) was used as a probe. Rat fibulin-2-specific messengers were detected by Northern blot hybridization as a large band at the position of $28 \mathrm{~S}$ RNA, as found in mouse (Neubauer et al. 1996).

In addition, to confirm the specificity of this probe, a second probe generated by cloning RT-PCR products was produced. The specific primers for the PCR were designed (Devereux et al. 1984) from the conserved tract of the mouse fibulin-2 sequence (AC X75285; Pan et al. 1993a) coding for the EGF-like repeats. The primers were as follows: forward primer, 5'-ATC TCC CAA CAC CAT CCC AC-3'; reverse primer, 5'-TAT AGC CCT CTG CAC ACA GCA C-3', corresponding to positions 2024-2289 of the mouse sequence (AC X75285). An annealing temperature of $60^{\circ} \mathrm{C}$ was used. This second probe gave the same results as the original on Northern blot hybridizations, confirming the specificity for fibulin-2 of the probe generated by the differential mRNA display procedure.

Fibronectin Clone pFH154 was used to detect fibronectinspecific transcripts. It hybridizes to fibronectin messengers of $7.1 \mathrm{~kb}$ and has been described in detail elsewhere (Kornblihtt et al. 1984).

Glyceraldehyde-3-phosphate-dehydrogenase To validate Northern blot results, a clone carrying rat glyceraldehyde3-phosphate-dehydrogenase (GAPDH) cDNA (Fort et al. 1985) was used.

Probe labeling cDNA probes were ${ }^{32} \mathrm{P}$-labeled by random priming (fibulin-1, fibulin-2, and GAPDH) or nick translation (fibronectin); the ${ }^{32} \mathrm{P}$-labeled dCTP was purchased from Amersham (Munich, Germany) and had a specific activity $3000 \mathrm{Ci} / \mathrm{mmol}$. For hybridization, a solution activity of $10^{6} \mathrm{dpm} / \mathrm{ml}$ was used.
Cell isolation and culture

Rat hepatic stellate cells (HSCs), endothelial cells (ECs), and Kupffer cells of the liver (KCs) were isolated and purified as described previously (Knittel et al. 1992a, b, 1996a; Ramadori et al. 1990, 1991; Neubauer et al. 1995). Briefly, the liver was digested enzymatically with pronase and collagenase, and non-parenchymal liver cells were separated by a Nycodenz density gradient. HSCs were collected from the white top layer of the gradient. KCs and ECs were further purified by centrifugal elutriation according to Knook et al. (1977) and De Leeuw et al. (1983). By using a JE-6B elutriation rotor in a J2-21 centrifuge (Beckman Instruments, Palo Alto, CA) at $2500 \mathrm{rpm}, \mathrm{KCs}$ were removed at $55 \mathrm{ml} / \mathrm{min}$ and ECs at $19 \mathrm{ml} / \mathrm{min}$. HSCs, $\mathrm{KCs}$, and ECs were plated at a density of $2.5 \times 10^{5}$ (HSCs) or $5 \times 10^{5}$ (KCs) cells per milliliter culture medium in 24 well Falcon plates, in $1 \mathrm{ml}$ medium/well, or on LAB-TEK chamber slides (Nalge Nunc International, Naperville, Ill., USA), in $0.5 \mathrm{ml} \mathrm{medium/well.} \mathrm{They} \mathrm{were} \mathrm{cultured} \mathrm{in}$ DMEM (HSCs), ECBM (ECs), or M199 (KCs) supplemented with $10 \% \mathrm{FCS}, 100 \mathrm{U} / \mathrm{ml}$ penicillin, $100 \mathrm{mg} / \mathrm{ml}$ streptomycin, and 1\% L-glutamine. ECBM was additionally supplemented with $0.05 \%$ insulin, hbFGF $(1 \mathrm{ng} / \mathrm{ml})$, and hEGF (0.1 ng/ml).

Furthermore, freshly isolated HSC were plated for 7 days, released from the culture plates by trypsinization, and replated at a 1:4 split ratio. Passaged HSC were analyzed at confluency, which usually took place within 7 days (1st passage). The purity of the freshly isolated cells and cultured cells was assessed as stated earlier (Knittel et al. 1992a, 1996a, b, c, 1997b). Rat liver MFs were obtained by the outgrowth of primary non-parenchymal liver cell cultures.

Additional liver was digested as for the isolation of $\mathrm{KCs}$ and ECs, and the remaining procedures were also the same, except that, during stirring in the final enzymecontaining solution, the $\mathrm{pH}$ was not corrected to physiological levels in order to eliminate HSC. Finally, at the time of the centrifugal elutriation, a fraction enriched with MFs was collected at a flow rate of $23 \mathrm{ml} / \mathrm{min}$. This fraction was plated in 24-well Falcon plates (Becton Dickinson, Heidelberg, Germany) at a density of $5 \times 10^{5}$ cells per well in $1 \mathrm{ml}$ culture medium. Cells were cultured in DMEM supplemented with $15 \%$ FCS, $100 \mathrm{U} / \mathrm{ml}$ penicillin, $100 \mathrm{mg} / \mathrm{ml}$ streptomycin, and $1 \%$ L-glutamine. At confluency, which was usually reached within 7-10 days, cells were released from the culture plates by trypsinization and replated at a 1:4 split ratio onto 24-well Falcon plates, in $1 \mathrm{ml}$ medium/well, or on LAB-TEK chamber slides, in $0.5 \mathrm{ml}$ medium/well. MFs were again passaged by using the same experimental conditions at confluency; they were subcultured for 
several passages, the experiments shown in this study being performed with MFs of passages 1-6.

Hepatocytes were isolated by in situ perfusion of the rat liver with a collagenase-containing solution according to Seglen (1972) and Ramadori et al. (1983) and plated onto collagen-coated 6-well Falcon plates (Becton Dickinson) at $6.5 \times 10^{5}$ cells $/ \mathrm{ml}$, in $2 \mathrm{ml}$ culture medium per well. Hepatocytes were suspended in DMEM containing 10\% FCS for the first $4-6 \mathrm{~h}$ and $0.05 \%$ insulin plus $0.2 \%$ bovine serum albumin later.

The culture medium was replaced at 4-6 h (hepatocytes), 1 day (KCs and ECs), 2 days (HSCs), or 6-7 days (MFs) after plating and then every day in the case of hepatocytes, ECs, and KCs, every other day for HSCs, and twice a week for MFs. Cells were maintained in culture at $37^{\circ} \mathrm{C}$ under a $5 \% \mathrm{CO}_{2} / 95 \% \mathrm{O}_{2}$ atmosphere and $100 \%$ humidity.

To evaluate the purity of the cultures, HSCs were assessed by direct cell-counting methods, under a phasecontrast microscope, by intrinsic vitamin A autofluorescence (HSCs; Ramadori et al. 1987) and, at days 2 and 7 after plating, were tested by immunofluorescence for the presence of desmin, SMA, vWF, ED2, and albumin as stated earlier (Knittel et al. 1992a, b). HSC cultures showed only $<3 \%$ contamination with KCs (ED2 [CD163]-positive cells, resident macrophages); ECs and hepatocytes were not detectable. As assessed by immunocytochemistry and light microscopy, freshly isolated hepatocytes were at least $99 \%$ pure and showed only a low (approximately 1\%) contamination with nonparenchymal liver cells. Until day 3 of culture, $<1 \%$ contaminating desmin- and/or SMA-positive cells were detected in hepatocyte monolayers. During this period, hepatocytes maintained albumin positivity revealed by immunoprecipitation and Northern blot analysis. KCs cultures were more than $99 \%$ pure. ECs were contaminated with $2 \%$ HSC and with $8 \%-10 \%$ KCs.

During primary culture, a transformation from a socalled "quiescent"/"at an early stage of activation" HSC to an "activated" HSC, exhibiting characteristics common to smooth muscle cells and MFs, is observed (Ramadori et al. 1990; Ramadori 1991; Gressner and Bachem 1995; Pinzani 1995; Knittel et al. 1996a, b, c; Friedman 1996). By using morphology and SMA immunoreactivity as an activation parameter (Ramadori et al. 1990; Rockey et al. 1992), HSCs were found to be fully "activated" (MF-like morphology and $100 \%$ SMA-positive) at day 7 of primary culture. HSCs cultured for 2 days were mainly SMAnegative $(<5 \%$ SMA-positive cells) and star-shaped and were classified as HSCs "quiescent"/"at an early stage of activation".

All experiments were performed at least three individual times with tests for the three different cell preparations.
Stimulation of hepatocytes, HSCs, and MFs with TGF- $\beta 1$

Hepatocytes at day 1 after isolation, HSCs at day 2 and day 7 after plating, and MFs at the first and fourth passages at confluency were washed three times with Gey's balanced salt solution and incubated for $20 \mathrm{~h}$ in serum-reduced $(0.3 \%$ FCS) culture medium alone or with TGF- $\beta 1$ (at 0.1 or $1 \mathrm{ng} /$ $\mathrm{ml}$ ). The concentration of cytokine used was previously shown to have no cytotoxic effects (Knittel et al. 1997a).

\section{RNA extraction and Northern blot analysis}

Total RNA of HSCs, KCs, hepatocytes, and MFs was extracted from cell cultures at various time-points (days 2 and 7 after plating in the case of HSC, days 1 and 3 for KCs and hepatocytes, and from the 1st to 6th passage for $\mathrm{MF}$ ) and, in the case of HSCs, ECs, KCs, and hepatocytes, also from freshly isolated cells. Liver cells were lysed with guanidium isothiocyanate, and total RNA was extracted as described elsewhere (Knittel et al. 1992a, b). Whole rat tissues were lysed in guanidium isothiocyanate by means of mechanical homogenization, and total RNA was extracted as for cell cultures. Total RNA was resolved by agarose gel electrophoresis, transferred to nylon membranes, and hybridized with the cDNA probes described below. Total RNA $(5 \mu \mathrm{g})$ from cellular cultures or RNA $(10 \mu \mathrm{g})$ extracted from tissues was loaded onto each lane. Hybridization was performed for $2 \mathrm{~h}$ at $68^{\circ} \mathrm{C}$ by using the QuickHyb Kit (Stratagene, La Jolla, Calif.). Posthybridization washes were performed twice for $10 \mathrm{~min}$ each at room temperature and once for $2-10 \mathrm{~min}$ at $60^{\circ} \mathrm{C}$ in $2 \times$ standard saline citrate containing $0.1 \%$ SDS. Nylon filters were washed, dried, and exposed to X-ray films at $-80^{\circ} \mathrm{C}$. After adequate exposure $(24-48 \mathrm{~h}$ for normal exposure and 2-3 weeks for extended exposure), the filters were washed in hot $1 \mathrm{M}$ TRIS-EDTA buffer and then rehybridized. Hybridizations were performed with fibulin1, fibulin-2, and fibronectin probes and finally with GAPDH.

Northern blot results shown in figures are representative of several independent experiments.

\section{Real-time RT-PCR}

Reverse transcription of isolated total RNA was performed with MMLV reverse transcriptase (Invitrogen), according to the instructions of the manufacturer. Real-time PCR analysis of reverse (cDNAs) transcripts was performed with the Abi Prism Sequence Detection System 7000 (Applied Biosystems, Foster City, Calif., USA) following the manufacturer's instructions, with the Sybr-green reaction master mix (Invitrogen) and primers described elsewhere (Dudas et al. 2007). For detection of rat fibulin-1, the 
Fig. 1 Localization of extracellular matrix (ECM) proteins by peroxidase (a, c, e) or fluorescent $(\mathbf{b}, \mathbf{d})$ staining in normal rat livers around a portal space. Fluorescent staining is shown to illustrate double-labeling of the same section. a Fibulin-1. b Fibulin-2. c Fibronectin. d Von Willebrand factor (vWF). e Negative control. Bile ducts negative for fibulin-1, fibulin-2, and $\mathrm{vWF}$ (bold white arrows) and positive for fibronectin (black arrowheads) are indicated. Fibulin-1 and 2 are manifest in the vessel walls. Fibronectin stains the whole portal area and sinusoidal spaces. vWF stains the walls of portal vessels and shows a scattered distribution in the parenchyma. Bars $100 \mu \mathrm{m}$
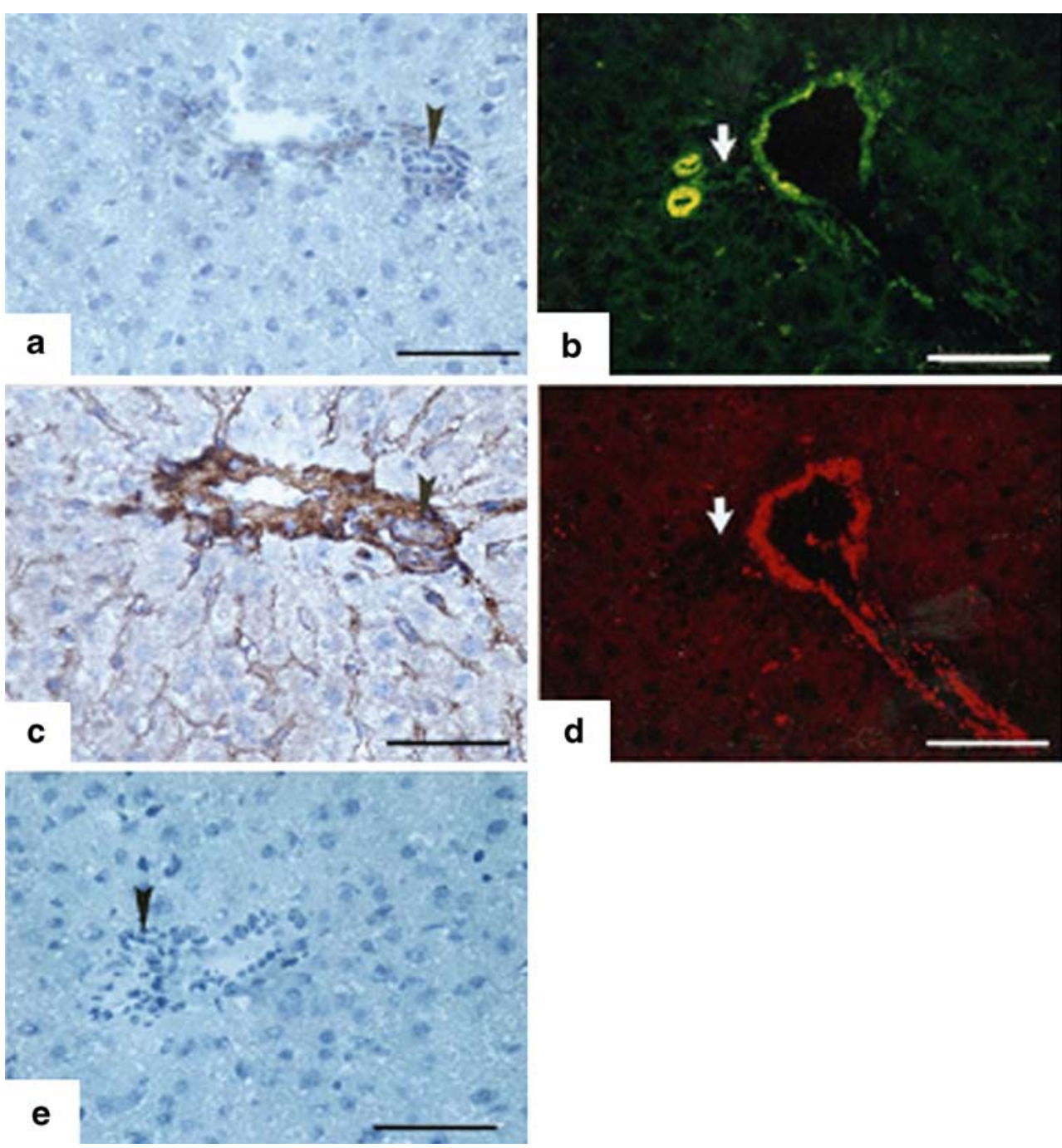

following primer sequences were used: forward, TTC CTG AGG AGG AAC AA; reverse, CCA CTG TGT TGA TGC AGG AT.

Primers were synthesized by MWG Biotech (Ebersberg, Germany) or by Invitrogen. The quantity of the PCR products of the genes of interest was determined based on the threshold PCR-cycle values (Ct-value), following the instructions of Applied Biosystems and was normalized with the quantities of the endogenous control (ubiquitin-C) PCR product (Raddatz et al. 2005).

The ubiquitin- $\mathrm{C}$ expression was not affected by the treatments in the investigated isolated cells and animal models. The normalized quantities of fibulin- 1 and fibulin-2 PCR products from treated animals were related to the values from control animals, and the relative expression was plotted against the observation time. In the isolated cells, the expression levels were determined by absolute quantification. In all cases, two or more series were analyzed in duplicate. Statistical significance $(\mathrm{P}<0.05)$ was tested with Student's $t$-test and one-way analysis of variance.

\section{Results}

Distribution of fibulin-1 and -2 in normal rat liver

Fibulin-1 in normal rat livers was localized in the vessels of portal spaces (Fig. 1) and central veins. No positivity for fibulin-1 was visible along the sinusoids. In accordance with published data (Knittel et al. 1999a, b; Tateaki et al. 2004), fibulin-2 immunoreactivity was low and was detectable in the portal space (Fig. 1).

Distribution of fibulin-1 and -2 in acute liver damage in rat

The distribution of fibulin-1 and -2 was analyzed in the $\mathrm{CCl}_{4}$ model. Livers were studied from $3 \mathrm{~h}$ onward until $96 \mathrm{~h}$ following $\mathrm{CCl}_{4}$ application, with an increase of fibulin-1 being most visible at $48 \mathrm{~h}$ after $\mathrm{CCl}_{4}$ administration (Fig. $2 \mathrm{f}$ ).

On the contrary, fibulin-2 expression was not modified by the acute liver injury and remained limited to the periportal space (Fig. 2g-1). 
Fig. 2 Fibulin-1 and -2 immunohistochemical localization in $\mathrm{CCl}_{4}$-induced acute rat liver injury. Immunofluorescent labeling (red) of fibulin-1 (a-f) or fibulin-2 (g-I) in control rat liver (a, g), and $3 \mathrm{~h} \mathrm{(b,} \mathrm{h),} 6 \mathrm{~h}$ (c, i), $12 \mathrm{~h}(\mathbf{d}, \mathbf{j}), 24 \mathrm{~h}(\mathbf{e}, \mathbf{k})$, and $48 \mathrm{~h}(\mathbf{f}, \mathbf{l})$ after $\mathrm{CCl}_{4}$-gavage (blue DAPI staining of nuclei). Original magnification: $200 \times$. Bars $100 \mu \mathrm{m}$
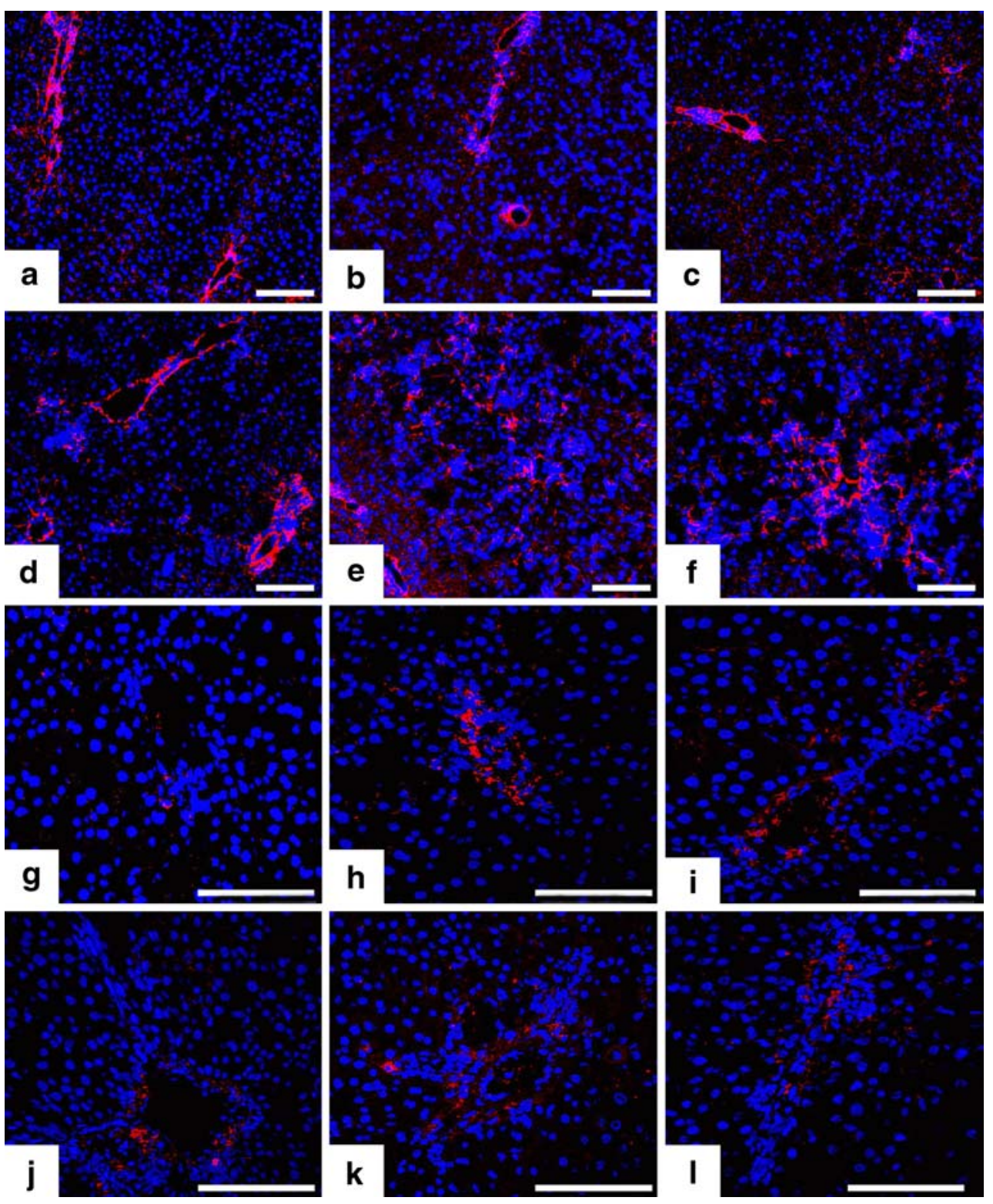

Distribution of fibulin-1 and -2 in rat fibrotic tissue

Fibulin-1 and -2 immunohistochemical staining increased after sequentially repeated $\mathrm{CCl}_{4}$ treatments. Specific antibody against fibulin-1 stained all the septa uniformly, both the smaller and larger ones, whereas the parenchyma became positive to a lower extent, and the sinusoids showed a weaker reaction (Fig. 3a, b). Fibronectin was also immunostained in the septa and sinusoids (Fig. 3c, d). The fibrotic septa appeared fibulin-2-positive (Fig. 3g, h). Immunostaining for fibulin-2 was also evident at the border between the scars and the parenchyma (Fig. $3 \mathrm{~g}, \mathrm{~h}$ ). The sinusoidal spaces were also occasionally positive with a scattered distribution (Fig. 3g, h). Fibulin-2 and vWF often showed co-localization (Fig. 3g-j).
Normal and cirrhotic human livers

The specific staining for fibulin- 1 and -2 was restricted to portal spaces (Fig. 4a, b) and central veins in normal human livers, similar to those in rat. In human cirrhosis, both fibulins were uniformly present in the septa and, at a low extent, also along the sinusoids (Fig. 4c, d); in particular, fibulin-2 showed a more extended localization than in the rat fibrotic livers and than fibulin-1 (Fig. 4c).

RNA analysis of normal and diseased rat livers

Northern blot analysis of total RNA from normal rat liver showed traces of fibulin-1-coding transcripts (Fig. 5). Two fibulin-1 transcripts corresponding to those 
Fig. 3 Localization of ECM proteins by peroxidase (a-f) and fluorescent (g-j) immunostaining in fibrotic rat livers $\left(\mathrm{CCl}_{4}\right.$ model). a, b Fibulin-1. c, d Fibronectin. e, f Negative control. g, h Fibulin-2. i, j vWF. $\mathbf{g}-\mathbf{j}$ Double-staining of the same section. Right Enlargement $(2 \times)$ of the main zone of interest in the corresponding left image (black arrowheads positivity along sinusoids, white arrows positivity along portal vessels). Bars $100 \mu \mathrm{m}$
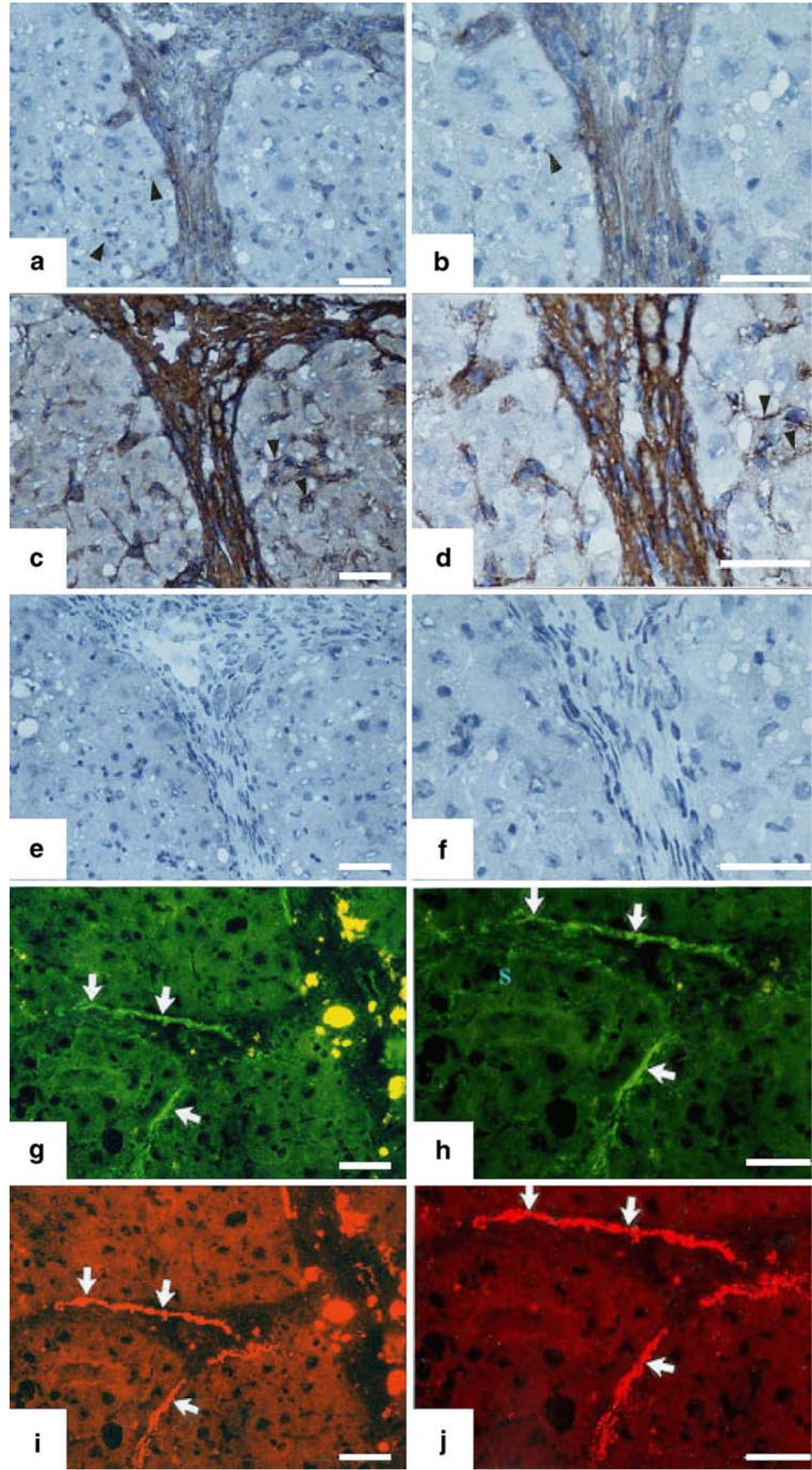
Fig. 4 Expression of fibulin-1 $(\mathbf{b}, \mathbf{d})$ and $-2(\mathbf{a}, \mathbf{c})$ in normal $(\mathbf{a}, \mathbf{b})$ and cirrhotic $(\mathbf{c}, \mathbf{d})$ human livers (a, c immunofluorescence staining, $\mathbf{b}, \mathbf{d}$ peroxidase staining). In normal liver, fibulin-1 and -2 expression is restricted to portal spaces (black arrowhead positivity for fibulin-1 in the portal vessel wall). In cirrhotic human liver, fibulin-1 positivity along sinusoids is scarce (black curved arrows), but scars are homogeneously positive. Similarly, fibulin-2 is homogeneously positive in the scars, and weak positivity is present along capillarized sinusoids (white curved arrows). Bars $100 \mu \mathrm{m}$
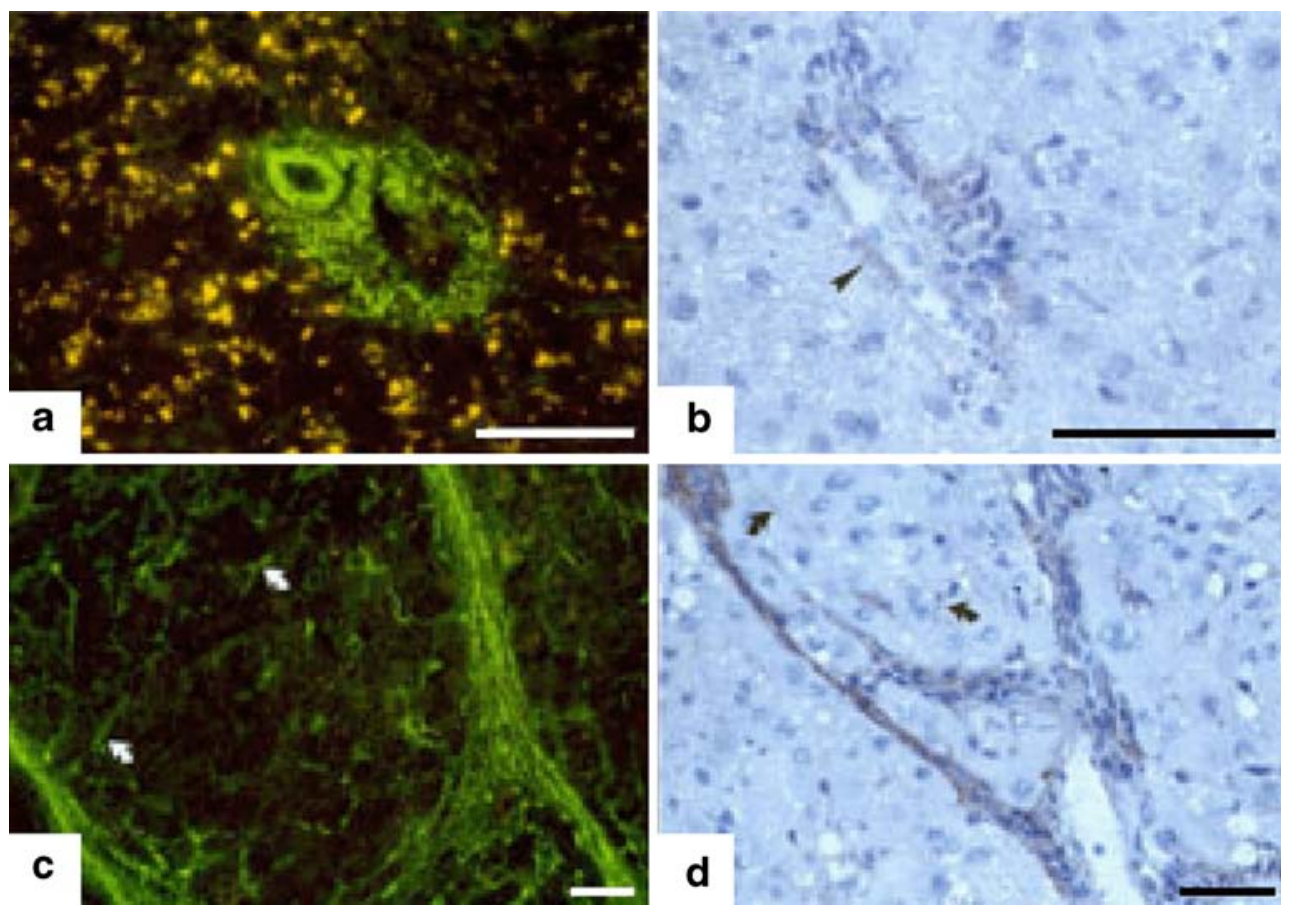

expected in humans and mice, namely at $2.4 \mathrm{~kb}$ and $2.7 \mathrm{~kb}$, were detected, coding respectively for the $\mathrm{C}$ and $\mathrm{D}$ variants of fibulin 1 (Pan et al. 1993a; Tran et al. 1997a). Fibulin-2-specific mRNAs were undetectable by Northern blot analysis of total RNA from normal rat liver, even after prolonged exposures of the films (normal exposure: 24-48 h; prolonged exposure: 2-3 weeks).

The quantification of fibulin-1- and fibulin-2-specific transcripts was carried out by real-time RT-PCR. The mRNA expression for fibulin- 1 and fibulin- 2 showed the following pattern: after $48 \mathrm{~h}$, the expression of fibulin-1specific transcripts considerably increased (17.23-fold related to control; Fig. 5 bottom, Fig. 6a). Fibulin-2 remained undetectable even after prolonged exposures of the films; nevertheless, by real-time RT-PCR, fibulin-2 was detected in normal rat liver and after acute liver injury and did not show significant changes in gene expression (Fig. 6a, Table 1).

In total RNA from fibrotic rat livers, the expression of fibulin-1-coding transcripts was 19.16-fold increased compared with normal rat liver (Fig. 5 top, Fig. 6b, Table 1). The specific mRNAs for fibulin-1 at $2.7 \mathrm{kDa}$ appeared more intense than those at $2.4 \mathrm{kDa}$ in liver cirrhosis (Fig. 5 top), whereas their intensity was similar at the peak-late times $(72 \mathrm{~h})$ after acute liver injury (Fig. 5 bottom). By real-time RT-PCR, both fibulin-1 and fibulin2 were significantly upregulated (19.16 and 26.47-fold, respectively) after repeated liver injury (Fig. 6b, c, Table 1).

\section{Cellular localization of fibulin-1 and -2}

In order to characterize the cellular sources of fibulin-1 and -2 , the expression of these ECM proteins was studied by Northern blot analysis and real-time RT-PCR in various rat
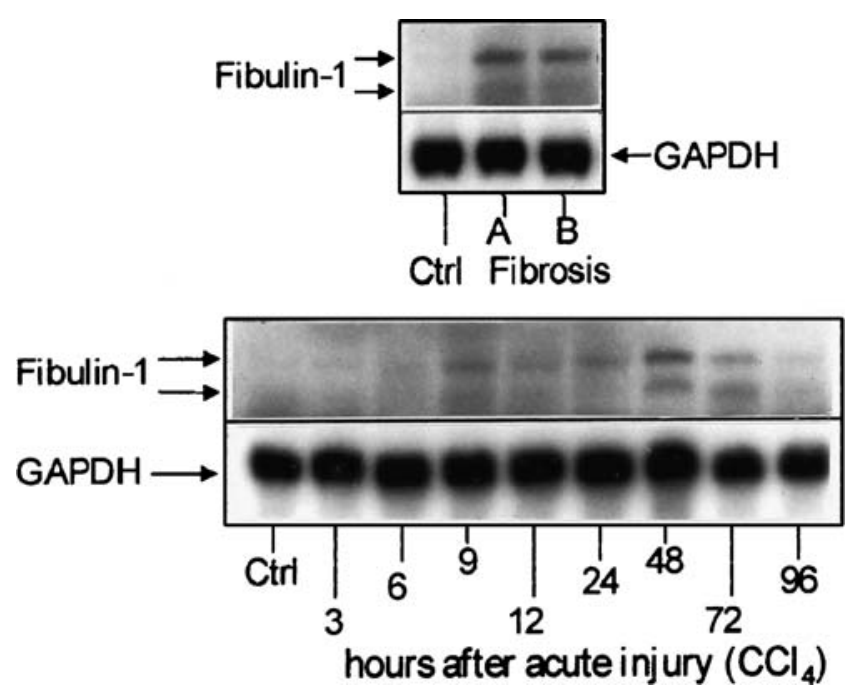

Fig. 5 Top Northern blot analysis of transcripts specific for fibulin-1 (double-bands at 2.4 and $2.7 \mathrm{~kb}$ corresponding, respectively, to the $\mathrm{C}$ and $\mathrm{D}$ variants) in control (Ctrl) and fibrotic (Fibrosis) rat livers $\left(\mathrm{CCl}_{4}\right.$ model). Glyceraldehyde-3-phosphate-dehydrogenase $(G A P D H)$ was used as a control of the RNA loading in the lane. No specific transcripts for fibulin-2 were detectable, even at much more prolonged exposures of the film $(A, B)$. Bottom Northern blot analysis of fibulin1 specific mRNAs after acute liver injury 

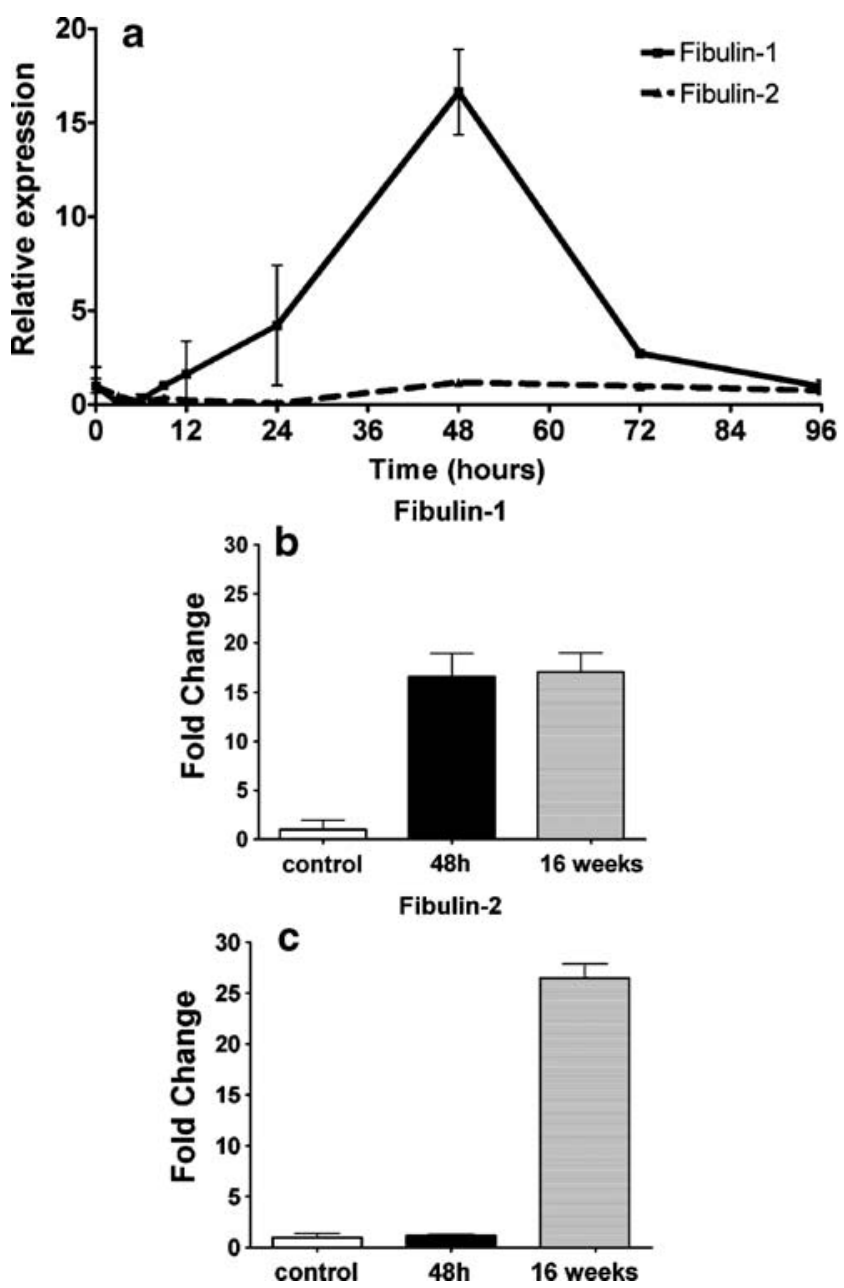

Fig. 6 Fibulin-1 and fibulin-2 relative mRNA expression in livers of single $\mathrm{CCl}_{4}$-treated rats (a), at the indicated time points after treatment, related to corn-oil-treated controls analyzed by real-time reverse transcription with the PCR. Comparison of fibulin-1 (b) and fibulin-2 (c) relative mRNA expression in livers after $48 \mathrm{~h}$ of single $\mathrm{CCl}_{4}$ treatment and after 16 weeks of repeated $\mathrm{CCl}_{4}$ treatment. The graphs plotted represent three independent treatment series after acute liver injury and five independent treatment series after chronic liver injury, in duplicate

Table 1 Changes in mRNA expression for fibulin-1 and fibulin-2 related to the expression level of control rat liver (given as the fold change) shown by real-time reverse transcription with the PCR (RT- liver cell populations. Fibulin-1-specific transcripts were detectable in cultured hepatocytes and in MFs (Table 2). They were absent from freshly isolated ECs, from KCs at all time-points, and from "quiescent"/“early stage of activation" HSCs (day 2 after plating) but were induced in fully "activated" HSC (day 7; Fig. 7, Table 2). Isolated hepatocytes, activated HSCs, and MFs expressed higher levels of fibulin-1 than normal rat liver (2.71-fold, 122.65-fold, and 469.48-fold, respectively).

Fibulin-2-specific transcripts were present in large amounts in MFs (1518-fold over the level of the normal rat liver) at all the passages tested. They were represented 3.1-fold over the expression level of normal liver in activated HSCs as shown by real-time RT-PCR (Table 2). Fibulin-2 appeared as a large band with a size of the $28 \mathrm{~S}$ ribosomal RNA in the total RNA isolate of rat liver MFs on Northern blots (Fig. 7). The large band is consistent with the existence of at least two different mRNA transcripts in rat cells, as reported in mice, where it is hypothesized to be attributable to the presence or absence of a single EGF-like repeat (Pan et al. 1993b).

HSCs either freshly isolated or at day 2 after plating, hepatocytes and KCs either freshly isolated or at day 1 and 3 of primary cultures, and ECs freshly isolated were also analyzed by Northern blot hybridization. No fibulin-2 mRNA expression was revealed, even after prolonged exposures of the films (Fig. 7).

The expression of fibulin-1-specific transcripts in fully "activated" HSCs was not modified significantly by stimulation with TGF- $\beta 1$ (Table 2); fibulin-2 gene expression was also not increased in HSC significantly after TGF$\beta 1$ exposure (Table 2). TGF- $\beta 1$ induced a significant 4.33-fold increased gene expression for fibulin-2 in hepatocyte cultures and a 2.62-fold increase in MF cultures (Table 2). TGF- $\beta 1$ had no effect on fibulin-1-coding mRNA in isolated rat hepatocytes or MFs (Table 2).

Collectively, the immunocytochemistry and Northern blot data indicated that the ECM proteins, fibulin-1 and

PCR) in acute and chronic liver damage. Ubiquitin-C was used as an endogeneous control. The expression levels in treated livers were compared with controls by Student's $t$-test

\begin{tabular}{|c|c|c|c|c|c|}
\hline \multicolumn{2}{|l|}{ Samples } & \multirow{2}{*}{$\begin{array}{l}\text { Fibulin-1, fold change } \\
1 \pm 0.70\end{array}$} & \multirow{2}{*}{$\frac{P \text {-value }(t \text {-test })}{-}$} & \multirow{2}{*}{$\begin{array}{l}\text { Fibulin-2, fold change } \\
1 \pm 0.38\end{array}$} & \multirow{2}{*}{$\frac{P \text {-value }(t \text {-test })}{-}$} \\
\hline Control & & & & & \\
\hline \multirow[t]{5}{*}{ Acute } & $6 \mathrm{~h}$ & $0.67 \pm 0.27$ & 0.455 & $0.13 \pm 0.09$ & 0.447 \\
\hline & $12 \mathrm{~h}$ & $1.63 \pm 0.67$ & 0.312 & $0.23 \pm 0.09$ & 0.177 \\
\hline & $24 \mathrm{~h}$ & $4.21 \pm 3.19^{*}$ & 0.008 & $0.34 \pm 0.01$ & 0.274 \\
\hline & $48 \mathrm{~h}$ & $17.23 \pm 0.97 * *$ & $10^{-8}$ & $1.18 \pm 0.97$ & 0.077 \\
\hline & $72 \mathrm{~h}$ & $2.72 \pm 0.95$ & 0.23 & $0.98 \pm 0.19$ & 0.055 \\
\hline Chronic & 16 weeks & $19.16 \pm 8.84^{* *}$ & $4.9 \times 10^{-5}$ & $26.47 \pm 1.42 * *$ & $3.3 \times 10^{-4}$ \\
\hline
\end{tabular}

*,**Significant changes 
Table 2 mRNA expression levels of fibulin-1 and fibulin-2 in hepatic stellate cells $(H S C)$, hepatocytes $(H C)$, and myofibroblasts $(M F)$ related to the expression level in control rat liver (in fold difference) by real- time RT-PCR (TGF $\beta 1$ transforming growth factor beta-1). Beta-actin was used as an endogeneous control. The expression levels in TGF- $\beta 1$ treated cells were compared with control cells by Student's $t$-test

\begin{tabular}{llllll}
\hline Samples & & Fibulin-1, fold difference & $P$-value $(t$-test $)$ & Fibulin-2, fold difference & $P$-value $(t$-test $)$ \\
\hline HSC, day 7 & Control & $122.65 \pm 22.36$ & - & $3.10 \pm 0.61$ & - \\
& $1 \mathrm{ng} / \mathrm{ml} \mathrm{TGF} \beta 1$ & $138.95 \pm 33.39$ & 0.243 & $13.12 \pm 8.94$ & 0.316 \\
HC & Control & $2.71 \pm 0.91$ & - & $0.12 \pm 0.09$ & - \\
& $1 \mathrm{ng} / \mathrm{ml}$ TGF $\beta 1$ & $2.37 \pm 0.54$ & 0.280 & $0.52 \pm 0.34 *$ & 0.027 \\
MF, passage 2 & Control & $469.48 \pm 57.28$ & - & $1517.99 \pm 24.25$ & - \\
& $1 \mathrm{ng} / \mathrm{ml} \mathrm{TGF} \beta 1$ & $463.65 \pm 52.79$ & 0.462 & $3988 \pm 898.04^{*}$ & 0.027 \\
\hline
\end{tabular}

*Significant changes

-2 , deposited in a fibrillar matrix, are synthesized in larger amounts by rat liver MFs than in other cell populations.

\section{Discussion}

Fibulins, like other ECM molecules, are associated with liver fibrosis, but their specific role is not fully understood. Moreover, the main liver cell population promoting the process of liver fibrogenesis remains uncertain (Ramadori and Saile 2002). No definitive evidence has been found for a "transdifferentiation" of HSCs to MFs. On the contrary, an increasing amount of data support the conviction that HSCs and MFs represent two similar but non-identical cell populations, the latter being comparable with those of other organs (Kinnman et al. 2003; Forbes et al. 2004).

In previous work, we first identified fibulin-2 as a specific marker of rat liver MFs in order to be able to distinguish these cells from other fibrogenic liver cell populations such as HSCs (Knittel et al 1997a, c). The present study aims to evaluate, in more detail, the expression patterns of fibulin-1 and -2 . Both proteins are present in the elastic fibers of normal hepatic vessels, in rat and in humans, according to previous publications (Roark et al. 1995; Zhang et al. 1995; Miosge et al. 1996, 1998).

Following acute liver damage, fibulin-1-specific mRNAs increase early after $\mathrm{CCl}_{4}$ administration and peak at $48 \mathrm{~h}$ (Figs. 5, 6). Interestingly, similar changes have not been seen for fibulin-2, whose specific mRNA levels and immunohistochemical expression remain unmodified throughout the observed kinetics of acute tissue damage and repair. Such divergent patterns of fibulin-1 and -2 might be related to the different properties of the two proteins and to the participation of different subsets of cell populations in the acute and chronic repair processes, at least in rats. In particular, the participation of hepatocytes in the synthesis of fibulin-1, which is also a circulating plasma protein, can be suggested. In addition, the peak of gene expression for fibulin-1 occurs $48 \mathrm{~h}$ after the $\mathrm{CCl}_{4}$ administration, when pericentral necrosis is detectable. At this time point, the maximal stimulation of HSCs might be expected. Fully activated HSC significantly contribute to fibulin-1 synthesis in the liver (Fig. 7. Table 2). Moreover, in view of the fibulin-2 pattern and the hypothesis of the participation of different subsets of cell populations, it is noteworthy that activated HSCs remain negative for fibulin2 after acute damage, whereas other molecules selectively expressed by activated HSC, such as neural cell adhesion molecule and glial fibrillary acidic protein, are reported to appear at the immunohistochemical level under the same conditions (Neubauer et al. 1996).

For the first time, we have shown that fibulin-1 and -2 are major components of the fibrotic septa not only in animal models, but also in humans and that their gene

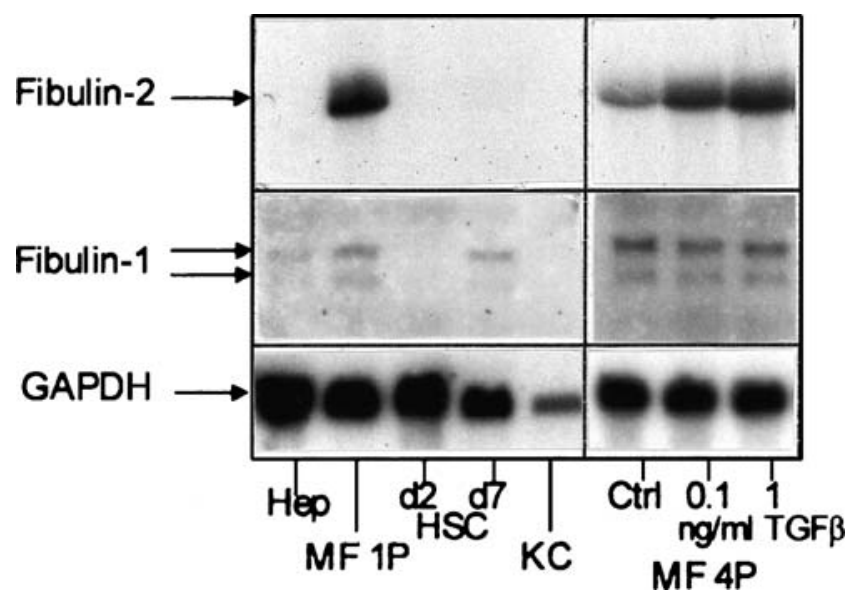

Fig. 7 Northern blot analysis of fibulin-1-specific (double-bands at 2.4 and $2.7 \mathrm{~kb}$, corresponding respectively to the $\mathrm{C}$ and $\mathrm{D}$ variants) and fibulin-2-specific transcripts (left) in the total RNA extracted from hepatocytes at day 3 (Hep), hepatic stellate cells (HSC) at day $2(d 2)$ and day $7(d 7)$ and Kupffer cells at day $3(K C)$ after plating and from myofibroblasts (MFs) at the first passage $(M F I P)$ and in the same transcripts (right) studied in MFs at the fourth passage $(M F 4 P)$ before $(C t r l)$ and after stimulation with transforming growth factor beta-1 $(T G F \beta-1)$ at two different concentrations $(0.1$ and $1 \mathrm{ng} / \mathrm{ml})$. Hybridization with GAPDH cDNA probe was used as an endogeneous control 
expression increases in liver fibrosis. Fibulin-1 stains both small and large septa homogeneously in rats. Fibulin-2, instead, shows a distribution, within the scars, that is not as uniform as the pattern for fibulin-1. Usually, the smallest septa are completely immunostained for fibulin-2. Larger septa are, instead, immunostained for fibulin-2 preferentially around portal vessels running inside them and along the outer lining of the scars. Specific staining for fibulin-2 occasionally appears along the sinusoids in rats and rather constantly and extensively in humans (Fig. 4).

The fibulin-2 positivity in this area is unexpected when one considers that HSC primary cultures have been found to stain negatively for fibulin-2, only limited cell groups showing a positive reaction. As regards the origin of the fibulin-2-positive cells in HSC cultures, the spotted distribution of fibulin-2 positivity has inspired us to consider fibulin-2-positive cells as being MFs contaminating HSC cultures, rather than a subpopulation of HSC (Knittel et al. 1999a, b). Possible explanations for perisinusoidal fibulin-2 detection, especially in human liver cirrhosis, are that "activated" HSC behave differently in vitro and during chronic damage in vivo, or that HSCs and liver MFs constitute a mixed population during chronic damage in vivo. However, as far as acute liver injury is concerned, the in vitro and in vivo patterns are closely correlated; in particular, no fibulin-2 expression is apparent, consistent with HSC being the principal mesenchymal cell type deputed to acute hepatic tissue repair.

In human liver cirrhosis, a greater induction of fibulin-2 has been detected than in the rat liver cirrhosis. This finding is consistent with the previous observations that more MFs might be present in human liver and in human liver cirrhosis (Dudas et al. 2009).

An additional finding of our study is that the relative increase of the two fibulin-1 variants $C$ and $D$ is not identical during acute and chronic hepatic tissue repair. After acute liver injury, the increase of the two isoforms is similar, whereas in chronic liver damage, a prevalence of isoform $\mathrm{D}$ is manifest. As shown by the analysis of in vitro cultures, the fibulin- 1 gene is expressed in a greater number of cell types than is fibulin-2, including both parenchymal and non-parenchymal cells. The synthesis of ECM proteins in hepatocytes has been previously reported (Chojkier et al. 1988) and raises the question of the role of parenchymal cells in the process of fibrogenesis (Dooley et al. 2008). Nevertheless, we should also take into consideration that primary cultures of isolated hepatocytes might be overgrown by mesenchymal cells, and the contaminating cell populations might express ECM proteins. Similar to other matrix proteins, fibulin-1 transcription is greatly enhanced in fully "activated" MF-like HSCs (day 7 after plating) with respect to HSCs "at an early stage of activation" (day 2 after plating; Ramadori 1991; Gressner and Bachem 1995;
Pinzani 1995; Knittel et al. 1996a, b, c; Friedman 1996), further confirming the role of activated HSCs in fibulin-1 deposition in chronic hepatic tissue repair. The gene expression for fibulin-1 is not regulated by the fibrogenic mediator TGF $\beta 1$ in any of the liver cells (hepatocytes, HSCs, and MFs) that express it, whereas fibulin-2 is responsive to TGF- $\beta 1$, at least in MFs. This confirms that fibulin-2-positive cells are not a more advanced fibrogenic subphenotype of HSCs. A low increase of the gene expression of fibulin-2 in hepatocyte cultures treated with TGF $\beta 1$ might be also attributable to contaminating MFs (Table 2).

In conclusion, these in vitro data confirm our previous results showing that HSCs and liver MFs are two similar, but non-identical, cell populations of the hepatic mesenchymal compartment. The participation of various liver cell populations in matrix synthesis might be different after acute and chronic liver injury. An understanding of the interactions among the different liver cell populations and their roles in the production of different ECM proteins might open up new and interesting perspectives in the field of liver fibrogenesis

Acknowledgments The authors are indebted to Anka Grundmann, Anke Herbst, and Sandra Georgi for excellent technical assistance.

Open Access This article is distributed under the terms of the Creative Commons Attribution Noncommercial License which permits any noncommercial use, distribution, and reproduction in any medium, provided the original author(s) and source are credited.

\section{References}

Argraves WS, Greene LM, Cooley MA, Gallagher WM (2003) Fibulins: physiological and disease perspectives. EMBO Rep 4:1127-1131

Baumann H, Gauldie J (1994) The acute phase response. Immunol Today 15:74-80

Chojkier M, Lyche K, Filip M (1988) Increased production of collagen in vivo by hepatocytes and nonparenchymal cells in rats with carbon tetracholoride-induced hepatic fibrosis. Hepatology 9:908-914

De Leeuw AM, Brouwer A, Barelds RJ, Knook DL (1983) Maintenance cultures of Kupffer cells isolated from rats of various ages: ultrastructure, enzyme cytochemistry, and endocytosis. Hepatology 3:497-506

Desmouliere A, Gabbiani G (1994) Modulation of fibroblastic cytoskeletal features during pathological situations: the role of extracellular matrix and cytokines. Cell Motil Cytoskel 29:195-203

Devereux J, Haeberli P, Smithies O (1984) A comprehensive set of sequence analysis programs for the VAX. Nucleic Acids Res 12:387-395

Dooley S, Hamzavi J, Ciuclan L, Godoy P, Ilkavets I, Ehnert S, et al (2008) Hepatocyte-specific Smad7 expression attenuates TGFbeta-mediated fibrogenesis and protects against liver damage. Gastroenterology 135:642-659

Dudas J, Mansuroglu T, Batusic D, Saile B, Ramadori G (2007) Thy-1 is an in vivo and in vitro marker of liver myofibroblasts. Cell Tissue Res 329:503-514 
Dudas J, Mansuroglu T, Batusic D, Ramadori G (2009) Thy-1 is an in vivo and in vitro marker of liver myofibroblasts. Histochem Cell Biol 131:115-127

Forbes SJ, Russo FP, Rey V, Burra P, Rugge M, Wright NA, Alison MR (2004) A significant proportion of myofibroblasts are of bone marrow origin in human liver fibrosis. Gastroenterology 126:955-963

Fort P, Marty L, Piechaczyk M, Sabrouty SE, Dani C, Jeanteur P, Blanchard JM (1985) Various adult tissues express only one major mRNA species from the glyceraldehyde-3-phosphate-dehydrogenase multigenic family. Nucleic Acids Res 13:1431-1442

Friedman SL (1996) Hepatic stellate cells. Prog Liver Dis 14:101-130

Gressner AM, Bachem MG (1995) Molecular mechanisms of liver fibrogenesis - a homage to the role of activated fat-storing cells. Digestion 56:335-346

Hesselson D, Kimble J (2006) Growth control by EGF repeats of the C. elegans fibulin-1C isoform. J Cell Biol 175:217-223

Kinnman N, Francoz C, Barbu V, Wendum D, Rey C, Hultcrantz R, Poupon R, et al (2003) The myofibroblastic conversion of peribiliary fibrogenic cells distinct from hepatic stellate cells is stimulated by platelet-derived growth factor during liver fibrogenesis. Lab Invest 83:163-173

Knittel T, Ramadori G (1994) Current concepts of liver fibrosis. Forum Trends Exp Clin Med 4:236-257

Knittel T, Armbrust T, Schwšgler S, Schuppan D, Meyer zum Büschenfelde K-H, Ramadori G (1992a) Distribution and cellular origin of undulin in the rat liver. Lab Invest 67:779-787

Knittel T, Schuppan D, Meyer zum Büschenfelde K-H, Ramadori G (1992b) Differential expression of collagen types I, III, and IV by fat-storing (Ito) cells in vitro. Gastroenterology 102:1724-1735

Knittel T, Armbrust T, Neubauer K, Ramadori G (1995) Expression of von Willebrand factor in normal and diseased rat livers and in cultivated liver cells. Hepatology 21:470-476

Knittel T, Aurisch S, Neubauer K, Eichhorst S, Ramadori G (1996a) Cell type specific expression of neural cell adhesion molecule (N-CAM) in Ito cells of rat liver: up-regulation during in vitro activation and in hepatic tissue repair. Am J Pathol 149:449-462

Knittel T, Fellmer P, Ramadori G (1996b) Gene expression and regulation of plasminogen activator inhibitor type $\mathrm{I}$ in hepatic stellate cells of rat liver. Gastroenterology 111:745-754

Knittel T, Janneck T, Müller L, Fellmer P, Ramadori G (1996c) Transforming growth factor- $\beta 1$ regulated gene expression of Ito cells. Hepatology 24:352-360

Knittel T, Fellmer P, Müller L, Ramadori G (1997a) Bone morphogenetic protein- 6 is expressed in non parenchymal liver cells and upregulated by transforming growth factor- $\beta 1$. Exp Cell Res 232:263-269

Knittel T, Fellmer P, Neubauer K, Kawakami M, Grundmann A, Ramadori G (1997b) The complement activating protease P100 is expressed by hepatocytes and is induced by IL- 6 in vitro und during the acute phase reaction in vivo. Lab Invest 77:221-230

Knittel T, Müller L, Saile B, Ramadori G (1997c) Effect of tumor necrosis factor-alpha on proliferation, activation and protein synthesis of rat hepatic stellate cells. J Hepatol 27:1067-1080

Knittel T, Kobold D, Saile B, Grundmann A, Neubauer K, Piscaglia F, Ramadori G (1999a) Rat liver myofibroblasts and hepatic stellate cells: different cell populations of the fibroblast lineage with fibrogenic potential. Gastroenterology 117:1205-1221

Knittel T, Kobold D, Piscaglia F, Saile B, Neubauer K, Mehde M, Timpl R, et al (1999b) Localization of liver myofibroblasts and hepatic stellate cells in normal and diseased rat livers: distinct roles of (myo-)fibroblast subpopulations in hepatic tissue repair. Histochem Cell Biol 112:387-401

Knook DL, Blansjaar N, Sleyster EC (1977) Isolation and characterization of Kupffer and endothelial cells from the rat liver. Exp Cell Res 109:317-329
Kornblihtt AR, Vibe-Pedersen K, Baralle FE (1984) Human fibronectin: molecular cloning evidence for two mRNA species differing by an internal segment coding for a structural domain. EMBO J 3:221-226

Martinez-Hernandez A (1985) The hepatic extracellular matrix. II. Electronimmunohistochemical studies in rats with $\mathrm{CCl}_{4}$-induced cirrhosis. Lab Invest 53:166-186

Miosge N, Gotz W, Sasaki T, Chu ML, Timpl R, Herken R (1996) The extracellular matrix proteins fibulin-1 and fibulin-2 in the early human embryo. Histochem J 28:109-116

Miosge N, Sasaki T, Chu M, Herken R, Timpl R (1998) Ultrastructural localization of microfibrillar fibulin-1 and fibulin-2 during heart development indicates a switch in molecular associations. Cell Mol Life Sci 54:606-613

Neubauer K, Knittel T, Armbrust T, Ramadori G (1995) Accumulation and cellular localisation of fibrinogen/fibrin during short term and long term rat liver injury. Gastroenterology 108:1124-1135

Neubauer K, Knittel T, Aurisch S, Fellmer P, Ramadori G (1996) Glial fibrillary acidic protein - a cell type specific marker protein for Ito cells in vivo and in vitro. J Hepatol 24:719-730

Pan TC, Kluge M, Zhang RZ, Mayer U, Timpl R, Chu ML (1993a) Sequence of extracellular mouse protein BM-90/fibulin and its calcium-dependent binding to other basement-membrane ligands. Eur J Biochem 215:733-740

Pan TC, Sasaki T, Zhang RZ, Fassler R, Timpl R, Chu ML (1993b) Structure and expression of fibulin-2, a novel extracellular matrix protein with multiple EGF-like repeats and consensus motifs for calcium binding. J Cell Biol 123:1269-1277

Pinzani M (1995) Novel insights into the biology and physiology of the Ito cell. Pharmacol Ther 66:387-412

Raddatz D, Bockemuhl M, Ramadori G (2005) Quantitative measurement of cytokine mRNA in inflammatory bowel disease: relation to clinical and endoscopic activity and outcome. Eur J Gastroenterol Hepatol 17:547-557

Ramadori G (1991) The stellate cell (Ito-cell, fat-storing cell, lipocyte, perisinusoidal cell) of the liver. New insights into pathophysiology of an intriguing cell. Virchows Arch B Cell Pathol 61:147-158

Ramadori G, Saile B (2002) Mesenchymal cells in the liver-one cell type or two? Liver 22:283-294

Ramadori G, Lenzi M, Dienes HP, Meyer zum Büschenfelde K-H (1983) Binding properties of mechanically and enzymatically isolated hepatocytes for $\operatorname{IgG}$ and C3. Liver 3:358-368

Ramadori G, Rieder H, Knittel T, Dienes H, Meyer zum Büschenfelde K-H (1987) Fat storing cells (FSC) of rat liver synthesize and secrete fibronectin. Comparison with hepatocytes. J Hepatol 4:190-197

Ramadori G, Veit T, Schwšgler S, Dienes H, Knittel T, Rider H, Meyer zum Büschenfelde K-H (1990) Expression of the gene of the $\alpha$-smooth muscle actin isoform in rat liver and in rat fatstoring (Ito) cells. Virchows Arch B Cell Pathol 59:349-357

Ramadori G, Schwšgler S, Veit T, Rieder H, Chiquet-Ehrismann R, Mackie EJ, Meyer zum Büschenfelde K-H (1991) Tenascin gene expression in rat liver and in rat liver cells. In vivo and in vitro studies. Virchows Arch B Cell Pathol 60:145-153

Ramadori G, Knittel T, Saile B (1998) Fibrosis and altered matrix synthesis. Digestion 59:372-375

Reinhardt DP, Sasaki T, Dzamba BJ, Keene DR, Chu ML, Gohring W, Timpl R, et al (1996) Fibrillin-1 and fibulin-2 interact and are colocalized in some tissues. J Biol Chem 271:19489-19496

Roark EF, Keene DR, Haudenschild CC, Godyna S, Little CD, Argraves W (1995) The association of human fibulin-1 with elastic fibers: an immunohistological, ultrastructural, and RNA study. J Histochem Cytochem 43:401-411

Rockey D, Boyles J, Gabbiani G, Friedman S (1992) Rat hepatic lipocytes express smooth muscle actin upon activation in vivo and in culture. J Submicrosc Cytol Pathol 24:193-203 
Sasaki T, Kostka G, Gohring W, Wiedemann H, Mann K, Chu ML, Timpl R (1995a) Structural characterization of two variants of fibulin-1 that differ in nidogen affinity. J Mol Biol 245:241-250

Sasaki T, Gohring W, Pan TC, Chu ML, Timpl R (1995b) Binding of mouse and human fibulin-2 to extracellular matrix ligands. J Mol Biol 254:892-899

Seglen P (1972) Preparation of rat liver cells: effect of $\mathrm{Ca}^{2+}$ on enzymatic dispersion of isolated perfused liver. Exp Cell Res 74:450-454

Strom A, Olin AI, Aspberg A, Hultgardh-Nilsson A (2006) Fibulin-2 is present in murine vascular lesions and is important for smooth muscle cell migration. Cardiovasc Res 69:755-763

Tateaki Y, Ogawa T, Kawada N, Kohashi T, Arihiro K, Tateno C, Obara M, et al (2004) Typing of hepatic nonparenchymal cells using fibulin-2 and cytoglobin/STAP as liver fibrogenesis-related markers. Histochem Cell Biol 122:41-49

Timpl R, Sasaki T, Kostka G, Chu ML (2003) Fibulins: a versatile family of extracellular matrix proteins. Nat Rev Mol Cell Biol 4:79-489
Tran H, Mattei M, Godyna S, Argraves WS (1997a) Human fibulin1D: molecular cloning, expression and similarity with S1-5 protein, a new member of the fibulin gene family. Matrix Biol $15: 479-493$

Tran H, VanDusen W, Argraves W (1997b) The self-association and fibronectin-binding sites of fibulin-1 map to calcium-binding epidermal growth factor-like domains. J Biol Chem 272:2260022606

Tsuda T, Wang H, Timpl R, Chu ML (2001) Fibulin-2 expression marks transformed mesenchymal cells in developing cardiac valves, aortic arch vessels, and coronary vessels. Dev Dyn 222:89-100

Zhang HY, Chu ML, Pan TC, Sasaki T, Timpl R, Ekblom P (1995) Extracellular matrix protein fibulin-2 is expressed in the embryonic endocardial cushion tissue and is a prominent component of valves in adult heart. Dev Biol 167:18-26

Zhang HY, Timpl R, Sasaki T, Chu ML, Ekblom P (1996) Fibulin-1 and fibulin-2 expression during organogenesis in the developing mouse embryo. Dev Dyn 205:348-364 